\title{
OPTIC DISC PIT MACULOPATHY IN A 13 YEARS OLD CHILD: A RARE CASE
}

\author{
Sandiyanto ${ }^{1}$, Weni Helvinda ${ }^{2}$ \\ 1,2 Department of Ophthalmology, Faculty of Medicine, Andalas University Dr.M.Djamil HospitalvPadang \\ Email: Sandi081088@gmail.com
}

\begin{abstract}
Introduction: Optic disc pit is a rare congenital abnormality of the optic disc. It is generally appears in the third or fourth decade of life; however, cases of serous detachment in children have been reported. Treatment includes argon laser to the peripapillary region, macular buckling surgery, vitrectomy combined with laser and/or gas injection.
\end{abstract}

Objective: To report a case with optic disc pit maculopathy in a 13 years old child.

Case Illustration: A 13 years old male presented to us with complaints of blurred vision in right eye started a month ago. No history of trauma. On examination, her visual acuities were 20/50 right and 20/20 left eye. Both anterior segments were normal, with normal intraocular pressures. OCT imaging showed optic disc pit located temporally, with associated serous macular detachment in the right eye.

Result: After 12 weeks observation, there is no significant change in the examination of the visual acuity, fundus examination and OCT imaging.

Conclusion: Currently there is no universally accepted treatment for optic disc pit maculopathy because the pathogenesis is not yet fully understood. In pediatric cases, 3-6 months of follow-up before any surgical and invasive procedures is appropriate.

Keyword: Optic disc pit maculopathy, OCT imaging, observation.

\section{ABSTRAK}

Pendahuluan: Optik disk pit adalah kelainan kongenital yang jarang terjadi. Umumya terjadi pada dekade ketiga dan keempat, tetapi beberapa kasus ditemukan pada anak-anak. Penatalaksanaannya dengan laser argon untuk daerah perifer, operasi macular buckling, atau vitrektomi kombinasi dengan laser atau injeksi gas.

Presentasi Kasus: Anak laki-laki usia 13 tahun dengan keluhan utama penglihatan mata kanan kabur sejak 1 bulan yang lalu. Tidak ada riwayat trauma. Tajam penglihatan mata kanan 20/50 dan mata kiri 20/20. Segmen anterior dan tekanan intraokular kedua mata normal. OCT memperlihatkan optik disk pit di temporal dengan serous macular detachment pada mata kanan.

Diskusi: Pasien ini diobservasi karena usia muda, tajam penglihatan baik, dan stabilnya kelainan selama observasi. Setelah 12 minggu, tidak ditemukan perubahan signifikan pada pemeriksaan tajam penglihatan, pemeriksaan funduskopi, dan OCT.

Kesimpulan: Saat ini tidak ada terapi baku untuk penatalaksanaan optik disk pit makulopati karena patogenesisnya masih belum sepenuhnya dimengerti. Pada kasus pediatrik, diperlukan follow up 3-6 bulan sebelum tindakan bedah dan prosedur invasif.

Kata Kunci: Optik disk pit makulopati, Pemeriksaan OCT, observasi. 


\section{PENDAHULUAN}

Optic disc pit (ODP) adalah kelainan kongenital pada diskus optikus berupa defek berbentuk oval atau bulat, berwarna abu-abu atau kekuningan karena kegagalan penutupan fissura optikus saat embriogenesis. ODP merupakan kelainan yang jarang terjadi, ditemukan kira-kira 1 dari 11.000 populasi. ODP dapat terjadi pada pria maupun wanita. ODP pertama kali dijelaskan pada tahun 1882 oleh Wiethe sebagai depresi berwarna abuabu gelap pada optic disc. Namun, ODP terkadang tampak berwarna putih atau kekuningan. Hampir $85 \%$ ODP ditemukan unilateral. Sekitar 70\% ODP ditemukan di temporal diskus optikus, $20 \%$ ditemukan pada daerah sentral dan sisanya terdapat di superior, inferior, dan nasal diskus optikus. ${ }^{1,2,3}$

ODP biasanya tidak menimbulkan gejala. Namun, sekitar $25-75 \%$ ODP dapat menyebabkan serous macular detachment yang dikenal dengan optic disc pit maculopathy (ODP-M). ODP-M umumnya muncul pada usia 30-40 tahun, tetapi dapat juga terjadi pada anak-anak. ODP- M diduga terjadi karena pencairan vitreus masuk ke ruang subretina atau intraretina melalui ODP. Patogenesis cairan subretina atau intraretina pada ODP-M masih belum diketahui dengan pasti, diduga dapat berasal dari vitreus, cairan serebrospinal, atau kebocoran pembuluh darah pada dasar ODP. Diagnosis pasien ini dapat ditegakkan dengan pemeriksaan funduskopi, Optical Coherence Tomography (OCT), atau fluorescein angiography (FFA).4,5,6

Pasien dengan ODP tidak membutuhkan terapi. Tindakan hanya dilakukan pada ODP-M. Penatalaksanaan secara konservatif awalnya dianjurkan pada pasien ODP-M, namun dengan tingkat keberhasilan terapi yang rendah, tindakan bedah lebih dipertimbangkan seperti laser fotokoagulasi, injeksi gas intravitreal atau kombinasi dengan laser, atau vitrektomi pars plana dikombinasi dengan injeksi gas intravitreal atau laser fotokoagulasi. Walaupun banyak tindakan yang dapat dilakukan dalam penatalaksanaannya, rekurensi terjadinya ODP-M setelah tindakan juga tinggi.

Saat ini, laser fotokoagulasi juga tidak direkomendasikan karena angka keberhasilan setelah tindakan masih rendah, tetapi laser fotokoagulasi yang disertai vitrektomi dilaporkan memiliki efektivitas yang lebih baik. Namun patogenesisnya yang masih kontroversial, sampai saat ini tidak ada konsensus terapi yang paling efektif pada kelainan ini. Reabsorpsi cairan subretina atau intraretina secara spontan dengan visus yang baik dilaporkan terjadi sekitar 25\% dari ODP$\mathrm{M}$, namun biasanya memiliki prognosis yang jelek.

Beberapa kepustakaan melaporkan terjadinya reabsorpsi spontan pada pasien ODP-M yang diobservasi saja tanpa pemberian terapi atau tindakan. ODP-M yang terjadi pada anak-anak atau dengan visus yang tidak buruk dapat dipertimbangkan untuk diobservasi 3-6 bulan sebelum melakukan tindakan. $3,7,8,9$

\section{KASUS}

Seorang pasien anak laki-laki, usia 13 tahun, datang ke poli mata RS M. Djamil Padang pada tanggal 28 Mei 2019, dengan penglihatan mata kanan terasa kabur sejak \pm 1 bulan yang lalu. Penglihatan dirasakan mendadak kabur dan bergelombang. Tidak ada riwayat trauma sebelumnya. Tidak ada riwayat menggunakan kacamata sebelumnya. 
Tidak ada keluarga dengan kelainan seperti ini. VOD: 20/50, VOS: 20/20. Segmen anterior dalam batas normal. TIO ODS $14 \mathrm{mmHg}$, posisi dan gerak bola mata dalam batas normal. Pada funduskopi tampak optic disc pit, oval, berwarna abu-abu di temporal diskus optikus OD, dan edema makula - diskus optikus OD. Pada pemeriksaan OCT tampak gambaran hiporefleksi intraretina dan subretina dari diskus optikus hingga makula OD, optic disc pit di temporal diskus optikus OD, dan edem makula - diskus optikus. Ketebalan retina sentral OD $443 \mu \mathrm{m}$. Ketebalan retina sentral OS $248 \mu \mathrm{m}$.
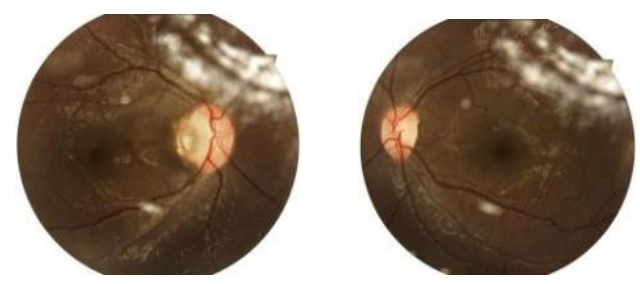

Gambar 1. Foto fundus OD OS
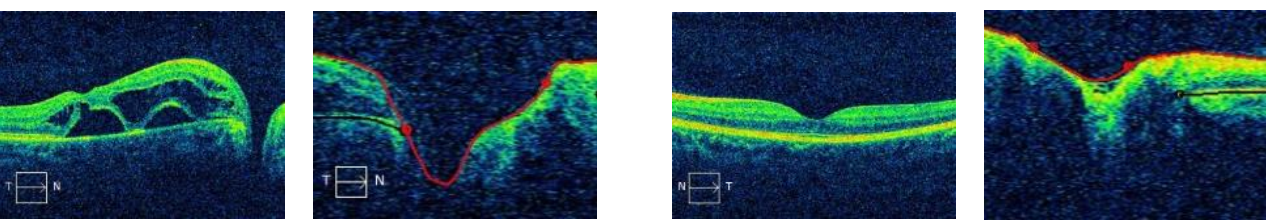

Gambar 2. Pemeriksaan OCT

Pasien ini didiagnosis dengan optic disc pit maculopathy OD dan di observasi setiap 2 minggu untuk melihat perubahan penyakit. Selama 12 minggu observasi tidak ditemukan perubahan yang signifikan pada ketebalan retina pasien ini dengan ketebalan retina sentral OD $461 \mu \mathrm{m}$
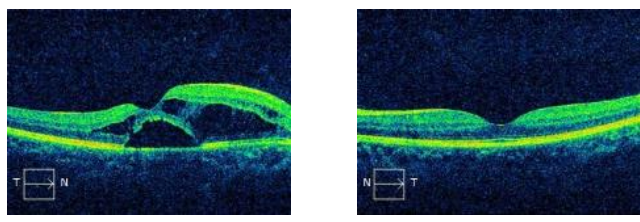

\section{Gambar 3. Pemeriksaan OCT pada minggu ke-12}

\section{DISKUSI}

Optic disc pit (ODP) pertama kali dijelaskan oleh Wiethe pada tahun 1882 pada seorang wanita usia 62 tahun sebagai area depresi pada bagian diskus optikus yang berwarna abu-abu gelap. ODP adalah suatu kelainan kongenital dimana terdapat defek pada diskus optikus yang terjadi karena kegagalan penutupan fissura optikus saat embriogenesis. Pada beberapa kasus sebelumnya dilaporkan ODP dapat diturunkan secara autosomal dominan. Optic disc pit maculopathy (ODP-M) adalah optic pit dengan adanya serous macular detachment yang merupakan perburukan dari ODP. 2,10,11

Berdasarkan kepustakaan, ODP tidak dipengaruhi oleh jenis kelamin. Prevalensi ODP dapat ditemukan sekitar 1 dari 11.000 populasi. ODP secara kongenital bervariasi 
dalam ukuran, bentuk, kedalaman, bahkan lokasi. Biasanya tampak kecil, hipopigmentasi, berwarna abu-abu, berbentuk oval atau bulat. Sekitar $85 \%$ ODP ditemukan unilateral dan $70 \%$ ODP ditemukan pada daerah temporal dari diskus optikus (gambar 1), $20 \%$ ditemukan pada daerah sentral dan sisanya dapat ditemukan pada daerah superior, inferior, dan nasal daridiskus optikus. ODP yang terletak ditepi dari diskus optikus sering menyebabkan lepasnya lapisan retina. ODP merupakan kelainan yang asimptomatik jika tidak ada perubahan sekunder pada makula. ODP dapat menyebabkan perubahan lapangan pandang, khususnya pit berukuran besar rentan menyebabkan lepasnya lapisan retina yang menyebabkan skotoma ataupun memperluas daerah bintik buta. Pada ODP dapat terjadi serous macular detachment sekitar $25-75 \%$ dan paling sering terjadi pada usia 30-40 tahun, diduga karena pencairan vitreus. Walaupun jarang, ODP-M juga dapat terjadi pada anak-anak dan tanpa adanya pencetus. Serous macular detachment dapat menyebabkan metamorfopsia atau pandangan kabur yang menunjukkan adanya skotoma sentral. ${ }^{2,3,4}$

\section{Gambar 4. ODP yang terletak di temporal diskus optikus ${ }^{4}$}

Pada laporan kasus ini, dilaporkan pasien laki-laki usia 13 tahun dengan ODP-M. Berdasarkan anamnesa didapatkan penglihatan mata kanan terasa kabur sejak 1 bulan yang lalu. Penglihatan dirasakan mendadak kabur dan bergelombang, tidak ada riwayat trauma dan menggunakan kacamata sebelumnya. Pemeriksaan visus pada mata kanan saat kunjungan pertama 20/50 dan tidak lebih baik dengan pinhole. Tajam penglihatan pasien ini relatif lebih baik jika dibandingkan dengan yang disebutkan pada kepustakaan. Disebutkan bahwa pasien ODP dengan keterlibatan makula umumnya ditemukan penurunan visus kurang dari 20/70, bahkan
$80 \%$ diantaranya mengalami penurunan visus lebih buruk dari 20/200. ${ }^{2}$ Pada pemeriksaan funduskopi ditemukan ODP, berbentuk oval, berwarna abu-abu, di temporal diskus optikus mata kanan. Hal ini sesuai dengan yang disebutkan pada kepustakaan mengenai struktur anatomi dan frekuensi ODP sering ditemukan unilateral dan terdapat di temporal diskus optikus., ${ }^{2,3}$ Pada pemeriksaan OCT tampak gambaran hiporefleksi pada intraretina dan subretina dari diskus optikus hingga makula.

Ada beberapa teori mengenai sumber dari cairan dan perubahan makula. Cairan intraretina dan subretina diduga dapat berasal 
dari cairan vitreus, ruang subarakhnoid atau kebocoran pembuluh darah retina yang terdapat pada diskus optikus (gambar 5). Namun, pemeriksaan FFA tidak selalu dapat menunjukkan sumber kebocoran cairan tersebut. Sumber cairan mungkin tidak sama pada setiap pasien karena perbedaan anatomi ODP. Sehingga sumber cairan dapat saja berasal dari vitreus, cairan serebrospinal atau dari keduanya. Mekanisme ODP menyebabkan pelepasan makular sampai saat ini juga masih belum diketahui. ${ }^{3,4,7}$

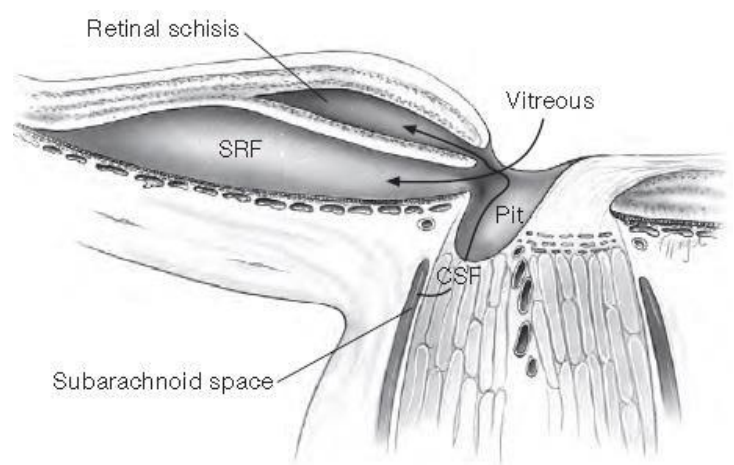

Gambar 5. Mekanisme terbentuknya ODP-M²

Bonnet menyebutkan serous macular detachment terjadi karena adanya tarikan dari vitreous. Hal ini disebutkan sebagai faktor penting dari patogenesis ODP yang menyebabkan cairan dari vitreous masuk ke ruang subretina yang berhubungan dengan pelepasan makula, selain faktor adhesi antara lapisan neurosensori retina dan RPE. Teori lainnya menyebutkan terdapat hubungan antara ruang subarakhnoid dan ruang subretina pada ODP yang menyebabkan cairan serebrospinal mengisi ruangan subretina. $4,7,12,13$

Pemeriksaan penunjang untuk menegakkan diagnosis ODP-M dapat dilakukan dengan pemeriksaan funduskopi, OCT, pemeriksaan lapangan pandang, dan FFA, atau pemeriksaan sederhana seperti amsler grid. Melalui funduskopi dapat terlihat morfologi pit dan perubahan yang terjadi pada makula. Pemeriksaan OCT dapat memperlihatkan adanya pemisahan lapisan retina karena adanya cairan yang mengisi antara lapisan dalam dan luar retina. Cairan dapat terlihat pada lapisan subretina maupun intraretina seperti sub internal limiting membran, inner nuclear layer atau outer nuclear layer. Pemeriksaan OCT pasien ini terlihat gambaran hiporefleksi intraretina dan subretina dari optic disc hingga makula OD. FFA biasanya tidak begitu signifikan dalam mendiagnosis kelainan ini. $3,5,14,15$ Pemeriksaan amsler grid mengkonfirmasi adanya metamorfopsia yang berhubungan dengan macular detachment pada pasien ini (gambar $6)$. 


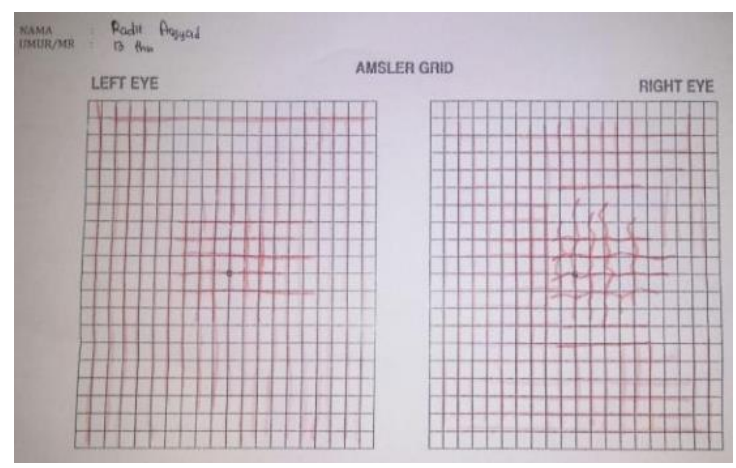

\section{Gambar 6. Pemeriksaan amsler grid}

Penanganan ODP berupa observasi

untuk melihat apakah terdapat keterlibatan dari makula. Dalam perkembangannya, penatalaksanaan ODP-M dapat dilakukan dengan observasi saja, terapi konservatif dengan kortikosteroid sistemik, laser fotokoagulasi, vitrektomi, dengan atau tanpa internal limiting membran (ILM) peeling, injeksi gas intravitreal, dilakukan sebagai tindakan tersendiri atau kombinasi satu dengan lainnya. Walaupun banyak metode berbeda yang telah dilakukan, sampai saat ini tidak ada konsensus yang menyebutkan metode paling efektif untuk penatalaksanaan kelainan ini. ${ }^{16,17}$

Pasien ODP-M biasanya memiliki prognosis visus pada jelek, walaupun perbaikan visus mungkin terjadi setelah serous macular detachment. Brown et al mengikuti perkembangan pada 20 mata pasien dengan ODP-M yang di observasi selama 5 tahun tanpa terapi, didapatkan ratarata visus mata pasien $20 / 80$. Tetapi, sangat kecil hubungan antara visus saat di diagnosa ODP-M dengan observasi jangka panjang. Dilaporkan terjadi resolusi spontan pada beberapa pasien. Namun, sebagian besar masih terdapat serous macular detachment setelah 5 tahun observasi. Pada anak-anak, observasi ODP-M dapat dipertimbangkan 3-6 bulan sebelum melakukan tindakan. 2,16,17
Pasien pada laporan kasus ini diobservasi, tidak diberikan terapi atau tindakan bedah dengan pertimbangan pasien masih muda dengan visus yang tidak buruk dan tidak mengganggu aktivitas, efek samping kortikosteroid jika diberikan untuk jangka waktu yang lama, efektivitas obat yang rendah, dan berbagai komplikasi tindakan bedah yang mungkin dapat terjadi jika dilakukan. Pemeriksaan visus, funduskopi, dan OCT dilakukan pada setiap kunjungan. Selama 12 minggu observasi, klinis pasien dan pemeriksaan OCT tidak mengalami perubahan yang signifikan. Masih ditemukan serous macular detachment dengan cairan intraretina dan subretina yang relatif sama. Selain untuk menentukan prognosis, pemeriksaan ini juga berguna untuk mengevaluasi pasien jika diperlukan tindakan. ${ }^{16,18}$

ODP-M sendiri merupakan kasus yang jarang terjadi pada anak-anak dan tidak ada bukti kuat untuk pemberian terapi yang efektif pada anak-anak. Oleh karena itu, penatalaksanaan ODP-M dengan observasi dapat dipertimbangkan karena sekitar 25\% kasus dilaporkan dapat terabsorpsi spontan. Pada salah satu kepustakaan dilaporkan sebuah kasus ODP-M pada anak laki-laki usia 6 tahun dengan visus mata kanan 20/32. Pasien ini diobservasi tanpa terapi dan mengalami reabsorpsi spontan pada akhir 
bulan ke 6 observasi dengan perbaikan visus menjadi 20/20 (gambar 7). Pemeriksaan OCT menunjukkan regresi lapisan retina yang sebelumnya memperlihatkan perubahan cystoid akibat penumpukan cairan dibawah lapisan internal limiting membran (gambar 8). Dari laporan kasus ini dapat disimpulkan bahwa reabsorpsi spontan ODP-M mungkin terjadi. ${ }^{17}$

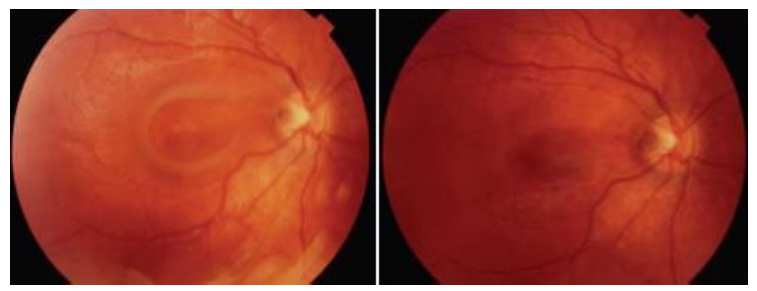

Gambar 7. Foto fundus pasien dengan ODP-M dan setelah 6 bulan observasi. ${ }^{17}$

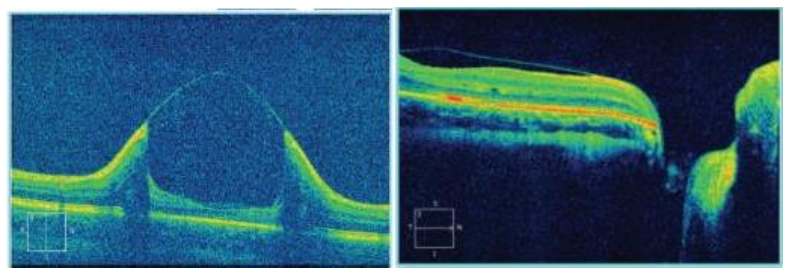

Gambar 8. Pemeriksaan OCT, awal dan setelah 6 bulan observasi. ${ }^{17}$

Pada kepustakaan lainnya dilaporkan kasus seorang pasien laki-laki usia 17 tahun dengan ODP-M mata kiri. Visus mata kiri saat pemeriksaan awal 20/200, dari foto fundus terlihat ODP pada bagian temporal diskus optikus dengan serous macular detachment meluas ke kuadran superior (gambar 9). Pemeriksaan OCT memperlihatkan lepasnya lapisan intraretina dan neurosensori retina. Pasien ini direncanakan vitrektomi pars plana dengan injeksi gas intravitreal tapi pasien menolak. Pasien diminta untuk kontrol secara teratur. Pada kunjungan hari ke-10 ditemukan peningkatan yang sangat bermakna, visus membaik hingga 20/30. Didapatkan perbaikan signifikan serous macular detachment dengan cairan subretina minimal dibandingkan sebelumnya (gambar 10). Follow up diteruskan hingga satu bulan, klinis pasien menetap dan tidak ditemukan perubahan pada pemeriksaan OCT. ${ }^{16}$

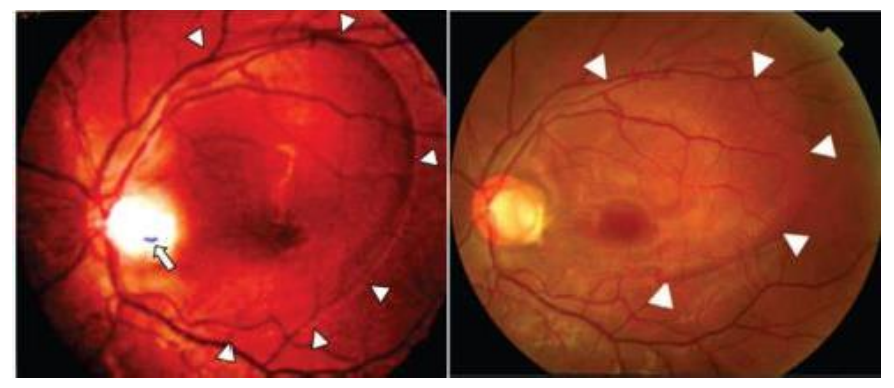

Gambar 6. Foto fundus pasien ODP-M, awal pemeriksaan dan 10 hari setelah observasi. ${ }^{16}$ 
JMJ, Volume 9, Nomor 2 Mei 2021, Hal. 22n 220 Candivanto, dkk. Optic Disc.....

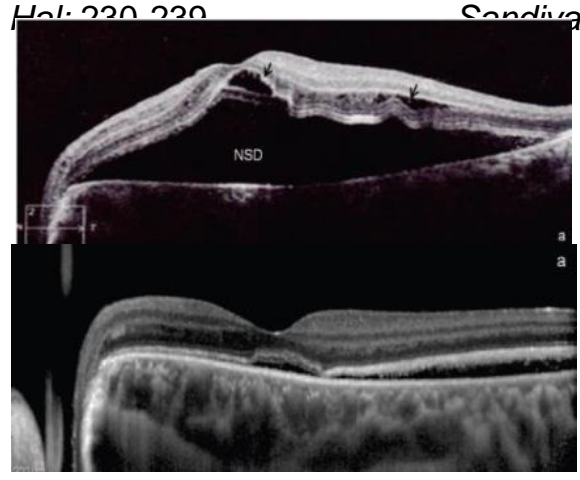

Gambar 10. OCT saat pemeriksaan awal dan 10 hari setelah observasi. ${ }^{16}$

Perbaikan ODP-M juga sudah dilaporkan pada beberapa kasus sebelumnya, umumnya terjadi setelah satu bulan hingga beberapa tahun. Visus dapat membaik tetapi biasanya tidak signifikan karena perubahan struktur RPE dan kerusakan lapisan retina yang berkaitan dengan lama lepasnya Iapisan retina tersebut. Patton et al melaporkan seorang pasien laki-laki usia 43 tahun yang mengalami reabsorpsi cairan subretina dengan kelainan serupa selama 2,5 tahun observasi dengan peningkatan visus dari 20/200 menjadi 20/60. Serupa dengan kasus lainnya, Cruzado-Sanchez et al melaporkan kasus reabsorpsi spontan long standing makular detachment yang berhubungan dengan ODP dengan perbaikan visus yang signifikan pada wanita usia 38 tahun. ${ }^{16}$

Dalam perkembangannya, awalnya ODP-M diterapi dengan pemberian kortikosteroid sistemik. Mekanisme kerjanya diduga dengan menurunkan tekanan intrakranial sehingga dapat mengurangi akumulasi cairan intraretinal dan subretina pada ODP-M. Namun, terapi ini tidak efektif dan ditemukan rekurensi yang besar setelah penghentian pemberian kortikosteroid. 3,4,16

Pada saat awal kelainan ini dikenal, laser fotokoagulasi pada daerah peripapil merupakan terapi pilihan dalam penatalaksanaannya. Secara teori, laser fotokoagulasi dilakukan untuk merusak lapisan serabut saraf, sehingga menyebabkan scar yang diharapkan menghambat cairan dari optic pit ke ruangan intraretina dan subretina. Meskipun beberapa penelitian melaporkan perbaikan dengan laser fotokoagulasi, namun saat ini tindakan laser fotokoagulasi tidak direkomendasikan karena angka keberhasilan terapi yang rendah, rekurensi ODP-M yang relatif tinggi setelah tindakan laser fotokoagulasi dan scar yang terbentuk dekat dengan sentral penglihatan menimbulkan skotoma baru yang menetap (gambar 11). Disebutkan juga bahwa tidak ada perbedaan yang bermakna antara visus akhir pasien ODP-M yang di observasi saja dengan pasien yang dilakukan laser fotokoagulasi. Namun, laser fotokoagulasi yang disertai vitrektomi dilaporkan memiliki efektivitas terapi yang lebih baik. $2,3,4,7$
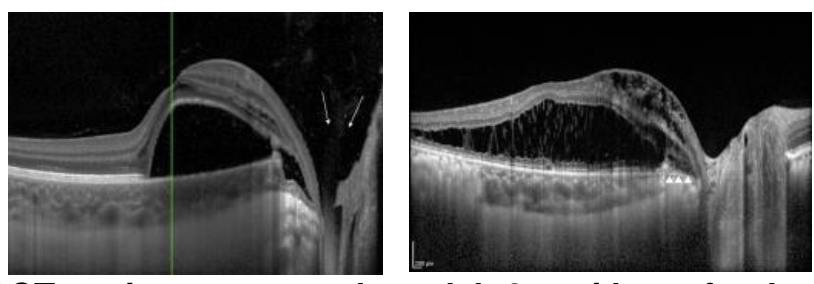

Gambar 11. OCT pasien yang gagal setelah 2 sesi laser fotokoagulasi ${ }^{4}$ 
Pada salah satu kepustakaan dilaporkan sebuah kasus ODP-M mata kanan pada anak perempuan usia 9 tahun yang tidak menunjukkan perbaikan dengan laser fotokoagulasi. Visus mata kanan pada awal pemeriksaan 20/50. Pasien di follow up 1 bulan, namun visus memburuk hingga 20/200. Pasien kemudian ditatalaksana dengan laser fotokoagulasi, namun setelah 2 bulan follow up tidak ada perbaikan. Selanjutnya direncanakan vitrektomi pars plana namun orang tua pasien menolak tindakan pada pasien ini. ${ }^{10}$

Untuk pasien dengan ODP-M dengan penurunan visus yang signifikan, pilihan tindakannya berupa vitrektomi pars plana dengan injeksi gas intravitreal dan laser fotokoagulasi. Vitrektomi pars plana dengan atau tanpa ILM peeling atau injeksi gas intravitreal merupakan suatu tindakan dengan tingkat keberhasilan yang tinggi pada ODP-M dimana cairan yang terdapat dalam vitreus dibuang dan diganti dengan gas intravitreal untuk mendorong kembali bagian retina yang terpisah ke tempat perlekatannya semula. Prinsip tindakan ini karena ODP-M yang terjadi diduga karena adanya tarikan dari vitreus. Dengan melepaskan tarikan tersebut akan membentuk penghalang permanen aliran cairan ke ruang intraretina dan subretina sehingga memperbaiki makular detachment. Tindakan ini relatif lebih sering digunakan oleh ahli vitreoretina dan memberikan perbaikan visus jangka panjang. $4,7,18,19$

Snead et al melaporkan keberhasilan kasus ODP-M yang ditatalakana dengan vitrektomi, endolaser dan injeksi gas intravitreal tanpa ILM peeling. Ishikawa et al melaporkan laser fotokoagulasi yang diikuti dengan vitrektomi, ILM peeling dan injeksi gas intravitreal juga memberikan hasil yang baik pada anak perempuan usia 7 tahun. Sedangkan Cox et al menyimpulkan kombinasi vitrektomi, injeksi gas intravitreal, dan laser fotokoagulasi lebih efektif daripada vitrektomi dengan injeksi gas intravitreal atau laser fotokoagulasi saja. $2,18,19,20$

Theodossiadis melaporkan macular buckling sebagai terapi utama dalam penatalaksanaan serous macular detachment. Tindakan ini dilakukan dengan memasang skleral spons di polus posterior bola mata pada daerah makula. Keberhasilan tindakan ini tergantung pada indentasi dan ketepatan posisi spons. Dengan membentuk indentasi, mekanismenya diduga dapat menghalangi aliran cairan intraretina yang berasal dari ODP. Follow up jangka panjang pada pasien ODP-M yang ditatalaksana dengan teknik ini menunjukkan tingkat keberhasilan dengan perbaikan visus yang tinggi dan rekurensi yang rendah. Namun, macular buckling merupakan tindakan bedah yang kompleks dan rumit sehingga jarang dilakukan. ${ }^{3,7}$

\section{KESIMPULAN}

Optic disc pit (ODP) adalah suatu kelainan kongenital yang jarang terjadi dimana terdapat defek pada diskus optikus dan dapat berkembang menjadi optic disc pit maculopathy (ODP-M). Patogenesa ODP-M sampai saat ini masih tidak diketahui, diduga cairan retina berasal dari vitreous, dari ruang subarakhnoid atau rembesan dari pembuluh darah retina yang terdapat pada diskus optikus.

Penatalaksanaan ODP-M sampai saat ini juga masih menjadi perdebatan. Dalam perkembangannya, observasi, 
kortikosteroid oral, laser fotokoagulasi, macular buckling, injeksi gas intravitreal dan vitrektomi pars plana dapat dipertimbangkan sebagai tindakan tersendiri atau kombinasi pada pasien dengan kelainan ini. Diagnosis pasien ini ditegakkan dari anamnesis, pemeriksaan funduskopi dan OCT. Pasien mengeluh metamorfopsia dan ditemukan ODP pada temporal diskus optikus disertai serous macular detachment. Pasien ini masih diobservasi dengan pertimbangan usia pasien masih muda, visus relatif baik, dan tidak ada perubahan signifikan selama 12 minggu observasi.

\section{REFERENSI}

1. Skuta GL, Canton LB, Weiss JS. Optic Pit Maculopathy. In: Retina and Vitreous. American Academy of Ophthalmology. San Francisco. 2014-2015. p; 294-5

2. Sadun AA, Khaderi KR. Optic Disc Anomalies, Pits, and Associated Serous Macular Detachment. In: Retina $5^{\text {th }}$ Ed Vol.1. China: Elsevier Mosby. 2013. p; 1583-7.

3. Uzel MM, Karacorlu M. Optic Disc Pit and Optic Disc Pit Maculopathy: a Review. In: Survey of Ophthalmology. Turkey. 2019. p; 1-35.

4. Jain N, Johnson MW. Pathogenesis and Treatment of Maculopathy Associated With Cavitary Optic Disc Anomalies. In: American Journal of Ophthalmology. California. 2014; 158(3): $p$ 423-35.

5. Tzu JH, Flynn HW, Berrocal AM, et al. Clinical Manifestations of Optic Pit Maculopathy as Demonstrated by Spectral Domain Optical Coherence Tomography. In: Clinical Ophthalmology. USA. 2013; 7: p 167-72.

6. Nagesha CK, Raman R, Gella L, Sharma

7. T. Optic Pit Maculopathy: A Review of Literature and Suggested Treatment Algorithm. In: Kerala Journal of Ophthalmology. India. 2014; 26(3): p 211 - 8.

8. Moisseiev E, Moisseiev J, Loewenstein A. Optic Disc Pit Maculopathy: When and How to Treat? A review of the Pathogenesis and Treatment Options. In: International Journal of Retina and Vitreous. Israel. 2015; 1(13): $p$ 1-9.

9. Cevher S, Keskek NS, Unal F, Demirduzen S, Oksuz H. Serous Macular Detachment Secondary to Optic Pit: Surgical Treatment and Long Time Results. In: Ophthalmological Medicine. turkey. 2016. p; 1-3.

10. Iftikhar M, Shah SMA, Goldberg MF. A Case of Optic Disc Pit Maculopath

11. Observed Without Intervention for 6years. In: Ophthalmology Retina. Baltimore. 2018. p; 1-8.

12. Oltulu R, Ersan I, Satirtav G, Okka M. Optic Disc Pit With Serous Macular Detachment in a Child. In: Dicle Medical Journal. turkey. 2013; 40(4): $p$ 678-80.

13. Upadhyay A, Nataraj A. Optic Disc Maculopathy. In: Kerala Journal of Ophthalmology. India. 2017; 28(2): p 133- 6 .

14. Steel DH, Suleman J, Murphy DC, et al. Optic Disc Pit Maculopathy. In: American Academy of Ophthalmology. UK. 2018. p; 1-9.

15. Chatziralli I, Theodossiadis P, Theodossiadis GP. Optic Disc Pit Maculopathy: Current Management Strategies. In: Clinical Ophthalmology. Yunani. 2018; 12: p 1417-22.

16. Oderinlo O, Hassan A, Okonkwo O. Fundus Autofluorescence Features of Optic Disc Pit Related Maculopathy. In: Nigerian Journal of Ophthalmology. Nigeria. 2015; 23(1): $p$ 27-30.

17. Sanghi G, Padhi TR, Warkad VU, et al. Optical Coherence Tomography Findings and Retinal Changes After Vitrectomy For Optic Disc Pit Maculopathy. In: Indian Journal of Ophthalmology. India. 2014; 62: $p$ 287-90.

18. Mehrotra N, Nagpal M, Jain H, Jain A. Early Spontaneous Reduction of Subsensory Fluid in A Case of Optic Disc Pit: A Rare Entity. In: Delhi Journal of Ophthalmology. India. 2018; 28: $p$ 38-40.

19. Bayar SA, Sezenöz AS, Pinarci EY, Yilmaz G. Spontaneous Regression of Optic Disc Pit Maculopathy in a Six-Year- Old Child. In: Turkish Journal of Ophthalmology. Turkey. 2017; 47: p 56-8.

20. Oderinlo O, Hassan A, Okonkwo O. Vitrectomy with Inner Retinal Fenestration For Optic Disc Pit Maculopathy. In: American Academy of Ophthalmology. Elvesier. 2014. p; 1-7.

21. Demir M, Guven D, Acar Z, Ergen E. Treatment of Serous Maculopathy Associated with Optic Disc Pit Without Vitrectomy: A Case Presentation. In: The Medical Bulletin of Sisli Etfal Hospital. Turkey. 2016; 50(1): $p$ 80-3.

22. Ozkaya A, Erdogan G. A Surgical Technique For Optic Pit Maculopathy: Vitrectomy Combined With Reserved ILM Flap. In: Beyoglu Eye Journal. Turkey. 2016; 1: $p$ 18-21. 